\title{
Renewal of Automatic Gage Control System for a Cold Tandem Mill with Electric Screwdowns
}

\author{
Yoshiro WASHIKITA, Masaaki OKAMOTO, ${ }^{1)}$ Toshiya OOI, ${ }^{2)}$ Yoshikazu MORI ${ }^{3)}$ \\ and Eiji HITOTSUMATSU ${ }^{3)}$
}

System Division, Sumitomo Metal Industries, Ltd., Fuso-cho, Amagasaki, Hyogo-ken, 660-0891 Japan.

1) Sumitomo Metal Steel Products, Inc., Dejimanishimachi, Sakai, Osaka-fu, 590-0831 Japan.

2) Kan-etsu Steel System Department, Sumitomo Metal Systems Development, Co. Ltd., Hikari, Kashima, Ibaraki-ken, $314-0014$

Japan. $\quad 3)$ Wakayama Steel Works, Sumitomo Metal Industries, Ltd., Minato, Wakayama, Wakayama-ken, $640-8555$

Japan.

(Received on March 18, 1998; accepted in final form on April 22, 1998)

\begin{abstract}
This paper describes renewal of automatic gage control (AGC) system for a cold tandem mill with electric screwdowns. Although gage control methods using high responsive actuators were researched, there is few research on the renewal of an old mill with low response actuators. We studied the way of improving gage accuracy without reconstructing actuators, from the viewpoint of saving cost.

Gage response to manipulation of the actuators depends on the frequency characteristics of the actuators and the rolling process, and the effect of $A G C$ was restricted by these frequency characteristics. We eliminated the frequency dependency of the gage response by inserting a dynamic compensator with reverse frequency characteristics in the control loop of $\mathrm{AGC}$, and expanded the controllable frequency range of the feedforward $A G C$ to a higher frequency. Moreover, in order to reduce the tension change caused by the gage control and to stabilize rolling force during acceleration and deceleration, we developed new tension control and rolling force control manipulating reduction in thickness. The combination of these controls and the feedforward AGC reduced gage deviation, keeping stable rolling.

The application of this AGC system to a cold tandem mill with electric screwdowns resulted in a great improvement in gage accuracy, and the accuracy has almost matched that of a newly constructed mill.
\end{abstract}

KEY WORDS: gage control; simulation; cold tandem mill; frequency characteristics; feedforward; feedback.

\section{Introduction}

Recently, customers' demands for gage accuracy has become more severe. It has become difficult for the automatic gage control (AGC) system of old-fashioned cold tandem mills to satisfy the demands. Hence, research on improving gage accuracy of these old mills and the renewal of the AGC system is a significant subject.

The recent research on gage control has been extended to the frequency characteristics of the rolling process, ${ }^{1-4)}$ and through the research, a method of decoupling the interaction between the gage and strip tension by means of a simultaneous manipulation of roll position and roll speed was developed. The application to a newly constructed cold tandem mill, ${ }^{5)}$ which was equipped with high responsive actuators such as hydraulic capsule and AC motors, resulted in excellent gage accuracy. ${ }^{3)}$

However, in an old mill, the responses of the actuators are not fast enough to apply the above method. Especially in a mill equipped with electric screwdowns, since the response of the roll position adjustment by the screwdowns is much slower than that of the main motors adjusting the roll speed, the simultaneous manipulation of the two actuators will not be so effective.
Therefore, we studied how to renew the automatic gage control system for a 5-stand cold tandem mill with electric screwdowns. According to the research of one of the authors, the gage response to manipulation of the actuators depends on the frequency characteristics of the actuators and the rolling process, ${ }^{3)}$ and the effect of AGC was restricted by these frequency characteristics. We eliminated the frequency dependency of the gage response by inserting a dynamic compensator with reverse frequency characteristics in the control loop of $\mathrm{AGC}$ and have expanded the controllable frequency range of the feedforward AGC to a higher frequency.

Moreover, in order to reduce the tension change caused by gage control and to stabilize rolling force during acceleration and deceleration, we developed tension control and rolling force control manipulating reduction in thickness. The combination of these controls and the feedforward AGC reduced gage deviation, keeping stable rolling.

The application of this AGC system for a cold tandem mill with electric screwdowns resulted in a great improvement of gage accuracy, and the accuracy has almost matched that of a newly constructed mill. 


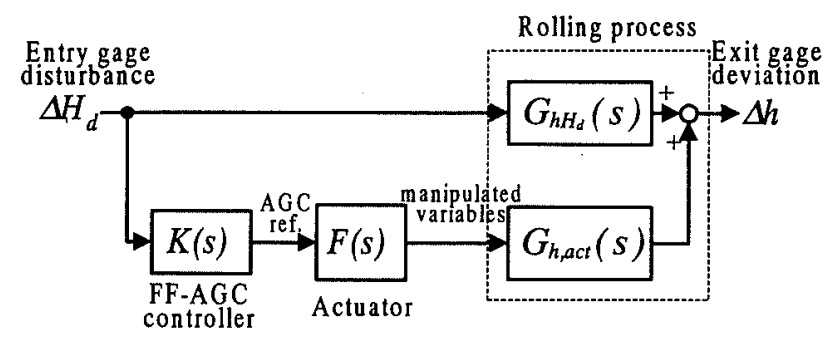

Fig. 1. Block diagram of feedforward gage control.

\section{Design of AGC System}

Automatic gage control consists of a feedforward gage control and a feedback gage control. In addition, the tension control and roll force control are significant to stabilize rolling and result in improving gage accuracy. We developed some methods in each control. The details will be described in the following subsections.

\subsection{Dynamic Feedforward Gage Controllers}

Since feedforward gage control (FF-AGC) has an interval between detecting entry gage deviation and outputting manipulated value, it can compensate for the response delay of the actuators and the rolling process. Thus, FF-AGC is more effective than the feedback gage control.

Figure 1 shows a block diagram of FF-AGC. $G_{h H_{d}}(s)$ is a transfer function from entry gage disturbance $\Delta H_{d}$ to exit gage deviation $\Delta h$ without gage control, and $G_{h, \text { act }}(s)$ is a transfer function from manipulated variables to $\Delta h$. $K(s)$ and $F(s)$ are transfer functions of the controller and actuators, respectively. When the response of roll position and roll speed are both fast enough $(F(s) \approx 1)$, the adequate combination of roll gap manipulation and roll speed manipulation can adjust the gain characteristics of $G_{h \text {,at }}(s)$ to cancel those of $G_{h H_{d}}(s) .{ }^{3)}$ Thus, $K(s)$ need not be a dynamic controller. However, when the response of the actuators are not so fast or only one actuator is manipulated, $K(s)$ should be a dynamic controller taking account of the frequency characteristics of $F(s), G_{h H_{d}}(s)$ and $G_{h, \text { act }}(s)$ to extend controllable frequency range.

According to the analysis of the static characteristics, ${ }^{6}{ }^{6}$ the main manipulated variable of $\# 2$ through $\# 5$ stand should be roll speed and the main manipulated variable of \#1 stand should be roll position. Furthermore, since the frequency characteristics of $G_{h H_{d}}(s)$ and $G_{h, \text { act }}(s)$ at \#1 stand are different from those at $\# 2$ through $\$ 5$ stand, as shown in Appendix, the structure of the controller $K(s)$ must be changed.

\subsubsection{Controller for $\# 2$ through $\# 5$ Stand}

At $\# 2$ through $\# 5$ stand, the response of the main motor, which controls roll speed, is given by

$$
F(s)=\frac{\omega_{v}^{2}}{s^{2}+2 \zeta_{v} \omega_{v} s+\omega_{v}^{2}}
$$

and $G_{h, \text { act }}(s)$ and $G_{h H_{d}}$ are expressed by

$$
G_{h, \mathrm{act}}(s)=c_{h V} \cdot \frac{1}{T s+1}
$$

$$
G_{h H_{d}}(s)=c_{h H_{d}} \cdot \frac{T^{\prime \prime} s+1}{T s+1}
$$

The function of FF-AGC is reducing the influence of disturbance of entry gage $\Delta H_{d}$ on exit gage deviation $\Delta h$. Consequently, the feedforward gage controller $K(s)$ must satisfy

$$
K^{\prime}(s)=-\frac{c_{h H_{d}}}{c_{h V}} \cdot \frac{\left(s^{2}+2 \zeta_{v} \omega_{v} s+\omega_{v}^{2}\right)\left(T^{\prime \prime} s+1\right)}{\omega_{v}^{2}}
$$

However, this controller is difficult to apply, because the relative degree is -3 . Therefore, a controller whose frequency characteristics resemble those of Eq. (4)

$$
K(s)=-\frac{c_{h H_{d}}}{c_{h V}} \cdot(a s+1) e^{b s}
$$

is proposed, where $e^{b s}$ means that the controller outputs $b$ second before the point measured by a thickness gage reaches the control stand. In general, only the direct gain in Eq. (5) is calculated and setup from the influence coefficients determined by the rolling theory. The addition of the dynamic compensation by $(a s+1) e^{b s}$ extends the controllable frequency range to a higher level. The parameters $a$ and $b$ which approximates $K^{\prime}(s)$ to $K(s)$ are obtained as follows.

First, noticing that $e^{b s}$ has nothing to do with gain of $K(s), a$ is determined to minimize

$$
J_{1}=\int\left\{\left|K^{\prime}(j \omega)\right|-|K(j \omega)|\right\}^{2} d \omega
$$

where $|K(j \omega)|$ denotes gain characteristic of $K(s)$. Next, $b$ is decided to minimize

$$
J_{2}=\int\left\{\angle K^{\prime}(j \omega)-\angle K(j \omega)\right\}^{2} d \omega
$$

where $\angle K(j \omega)$ denotes phase characteristic of $K(s)$.

Figure 2 shows an example of the calculated results of $a$ and $b$ for several roll speeds. Strip width is $1.19 \mathrm{~m}$, gage $0.6 \mathrm{~mm}, \zeta_{v} 0.9$, and $\omega_{v}$ is 15 . The parameters $a$ and $b$ increase, as the roll speed decreases, because $T^{\prime \prime}$ is inverse proportion to roll speed, as shown in Eq. (A-22). It should be noted that, when the strip is thinner or harder, since $T^{\prime \prime}$ is more sensitive to roll speed, $a$ and $b$ must be changed more severely, according to the roll speed.

Figure 3 shows the gain characteristics from entry gage disturbance $\Delta H_{d}$ to exit gage deviation $\Delta h$, when roll speed is $12.2 \mathrm{~m} / \mathrm{s}$. The gain characteristics are calculated by using Eqs. (A-12) and (A-13), which are more strict than Eqs. (2) and (3). Without the dynamic compensation $(a=b=0)$, FF-AGC is ineffective at the frequency over $2 \mathrm{~Hz}$. With an adequate $\mathrm{a}$ and $\mathrm{b}$ shown in Fig. 2, the controllable frequency range can be extended to $10 \mathrm{~Hz}$.

Figure 4 shows the structure of FF-AGC. The speed reference of $\mathrm{FF}-\mathrm{AGC}$ is calculated by multiplying the static gain and dynamic compensation factor by the entry gage disturbance. The static gain is set for every coil based on the partial differential coefficients. ${ }^{6)}$ The parameters $a$ and $b$ in the dynamic compensator are also determined for every coil as a function of roll speed, and 


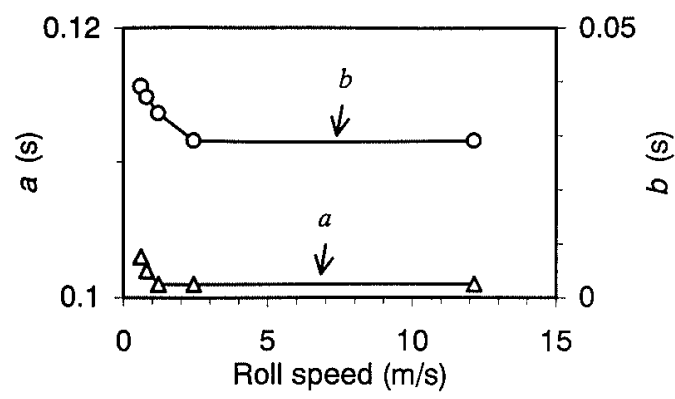

Fig. 2. Parameters of $¥ 2$ through $¥ 5$ feedforward gage controller.

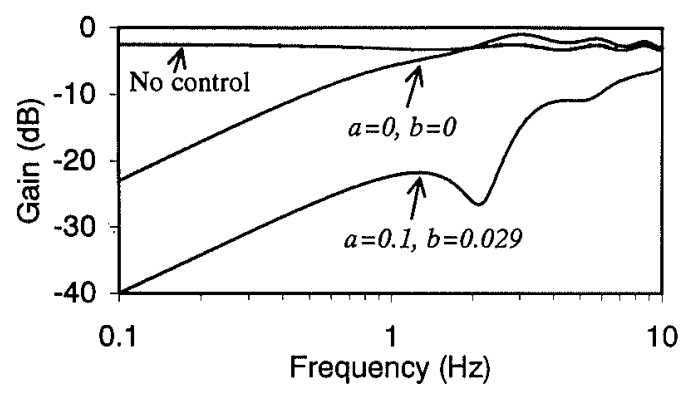

Fig. 3. Gain characteristics from entry gage to exit gage.

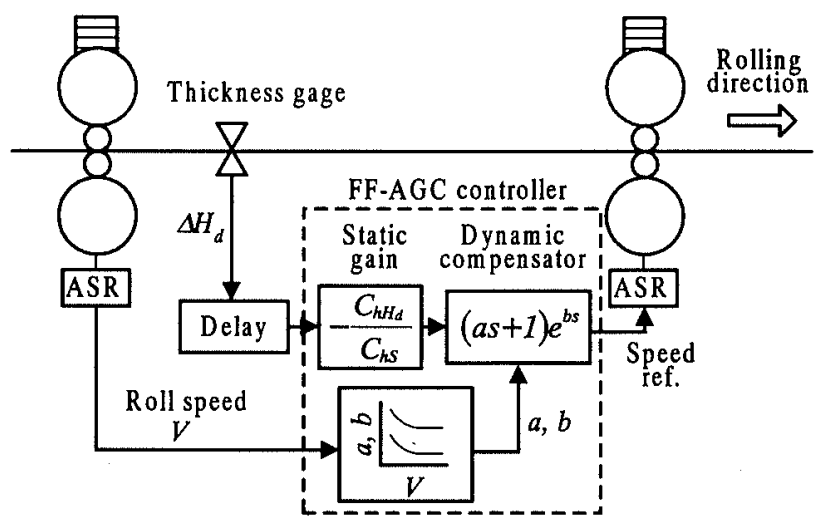

ASR: automatic speed regulator

Fig. 4. Feedforward gage control at $\# 2$ through $\# 5$ stand.

during the control, $a$ and $b$ are referred by the measured roll speed.

\subsubsection{Controller for $\# 1$ Stand}

At \#1 stand, the response of the actuator, which controls roll position, is given by

$$
F(s)=\frac{1}{T_{s} s+1}
$$

and $G_{h, \text { act }}(s)$ and $G_{h H_{d}}(s)$ are expressed by

$$
\begin{aligned}
& G_{h, \text { act }}(s)=c_{h s} \cdot \frac{s^{2}+2 \zeta^{\prime} \omega_{n} s+\omega_{n}^{2}}{s^{2}+2 \zeta \omega_{n} s+\omega_{n}^{2}} \\
& G_{h H_{d}}(s)=c_{h H_{d}} \cdot \frac{s^{2}+2 \zeta^{\prime \prime} \omega_{n} s+\omega_{n}^{2}}{s^{2}+2 \zeta \omega_{n} s+\omega_{n}^{2}}
\end{aligned}
$$

In order that the transfer function from $\Delta H_{d}$ to $\Delta h$ equals $0, K(s)$ should be

$$
K(s)=\frac{c_{h H_{d}}}{c_{h S}} \cdot \frac{\left(s^{2}+2 \zeta^{\prime \prime} \omega_{n} s+\omega_{n}^{2}\right)\left(T_{s} s+1\right)}{s^{2}+2 \zeta^{\prime} \omega_{n} s+\omega_{n}^{2}}
$$

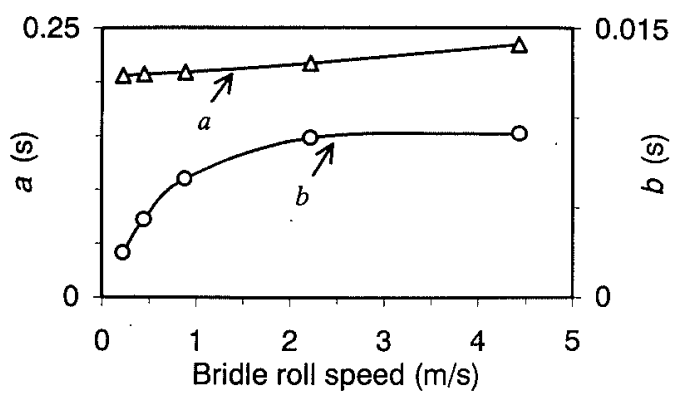

Fig. 5. Parameters of $\# 1$ feedforward gage controller.

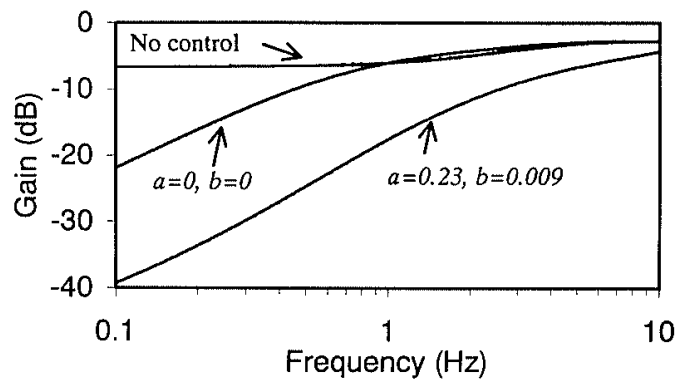

Fig. 6. Gain characteristics from entry gage to exit gage at \#1 stand.

Since the relative degree is $-1, K(s)$ is applicable. When $\omega_{n}$ is large enough, the controller can be simplified to

$$
K^{\prime}(s)=-\frac{c_{h H_{d}}}{c_{h S}} \cdot(a s+1) e^{b s}
$$

Figure 5 shows an example of calculated results of the parameters $a$ and $b$ for several bridle roll speeds. Strip width is $1.19 \mathrm{~m}$, gage $1.684 \mathrm{~mm}$, and $T_{S}$ is 0.21 . Contrary to Fig. 2, $a$ and $b$ decrease, as the bridle roll speed is slow, because, as shown in Eqs. (A-30), (A-32) and (A-33), $\omega_{n}$ is independent of bridle roll speed, and $\zeta^{\prime}$ and $\zeta$ "are in proportion to the speed. It should be noted that, when the strip is thin, since $\zeta^{\prime}$ and $\zeta^{\prime \prime}$ are more sensitive to the bridle roll speed, the parameters $a$ and $b$ must be changed more severely, according to the bridle roll speed.

Figure 6 shows the gain characteristics from entry gage disturbance $\Delta H_{d}$ to exit gage deviation $\Delta h$, when bridle roll speed is $4.4 \mathrm{~m} / \mathrm{s}$. Without the dynamic compensation $(a=b=0)$, FF-AGC is ineffective at the frequency over $1 \mathrm{~Hz}$. With an adequate $a$ and $b$ shown in Fig. 5, the controllable frequency range can be extended to $10 \mathrm{~Hz}$.

\subsection{Non-interactive Control in FB-AGC}

When roll speed is manipulated to control gage at $\# 2$ through \#5 stand, strip tension also changes. Especially in the feed back gage control (FB-AGC), since the control output is generally larger than that of the feedforward gage control (FF-AGC), sometimes the change of tension caused by FB-AGC disrupts stable rolling. The change of tension required for controlling gage is approximately in proportion to the target gage. It implies that gain of FB-AGC when manipulating only the roll speed should not be large in rolling a thick strip.

When the response of the actuators are fast enough, the simultaneous manipulation of roll position and roll speed completely removes the interference of the gage control and the tension control and extends the con- 
trollable frequency range. ${ }^{3)}$ We examined the effects of this method in a mill with electric screwdowns.

Considering only direct gains, to change the gage by $\Delta h_{\mathrm{ref}}$, roll speed $\Delta V_{\text {ref }}$ and roll position $\Delta S_{\text {ref }}$ should be referred by

$$
\left[\begin{array}{c}
\Delta V_{\mathrm{ref}} / V \\
\Delta S_{\mathrm{ref}}
\end{array}\right]=\operatorname{det}\left(\left[\begin{array}{cc}
G_{h V}(0) & G_{h S}(0) \\
G_{\sigma V}(0) & G_{\sigma S}(0)
\end{array}\right]\right) \cdot\left[\begin{array}{c}
G_{\sigma S}(0) \\
-G_{\sigma V}(0)
\end{array}\right] \Delta h_{\mathrm{ref}}
$$

where the elements of the matrices are calculated by Eqs. (A-11), (A-12), (A-14) and (A-15). On the other hand, when only the roll speed is manipulated, the manipulated values should be referred by

$$
\left[\begin{array}{c}
\Delta V_{\mathrm{ref}} / V \\
\Delta S_{\mathrm{ref}}
\end{array}\right]=\left[\begin{array}{c}
G_{h V}(0)^{-1} \\
0
\end{array}\right] \Delta h_{\mathrm{ref}}
$$

The transfer functions from $\Delta h_{\text {ref }}$ to the gage $\Delta h$ and tension $\Delta \sigma$ turn out to be

$$
\left[\begin{array}{c}
\Delta h(s) \\
\Delta \sigma(s)
\end{array}\right]=\left[\begin{array}{ll}
G_{h V}(s) & G_{h S}(s) \\
G_{\sigma V}(s) & G_{\sigma S}(s)
\end{array}\right]\left[\begin{array}{c}
G_{v}(s) K_{v} \\
G_{S}(s) K_{S}
\end{array}\right] \Delta h_{\mathrm{ref}}(s)
$$

where $G_{v}(s)$ and $G_{S}(s)$ are transfer functions of the actuators shown in Eqs. (1) and (8), respectively, and $K_{v}$ and $K_{S}$ are control gains from $\Delta h_{\text {ref }}$ to $\Delta V_{\text {ref }} / V$ and $\Delta S$, which are expressed by Eq. (13) or (14).

Figure 7 shows the gain characteristics of Eq. (15). Gage is $1.6 \mathrm{~mm}$ and $\Delta h_{\text {ref }} 0.016 \mathrm{~mm}, \zeta_{v} 0.9, \omega_{v} 15$, and $T_{S} 0.21$. The gain characteristics of $\Delta h$ is hardly improved by manipulating both the roll speed and the roll position because the response of the electric screwdowns are slow. However, the gain characteristics of $\Delta \sigma$ is clearly reduced. This simulation concludes that the non-interactive control is effective in the sense of suppressing the tension change caused by FB-AGC when rolling a thick strip.

\subsection{Exclusive Control for the Final Stand}

The control system for the final \#5 stand must be specially designed because of two reasons. One is that the rolling force needs to be controlled as well as the gage and strip tension, because it directly influences strip flatness and the roughness of the strip surface. The other is that manipulation of roll position at the final stand has much influence on the final gage next to the manipulation at $\# 1$ stand. ${ }^{6}$ ) Therefore, we developed rolling force monitor control and tension monitor control, which

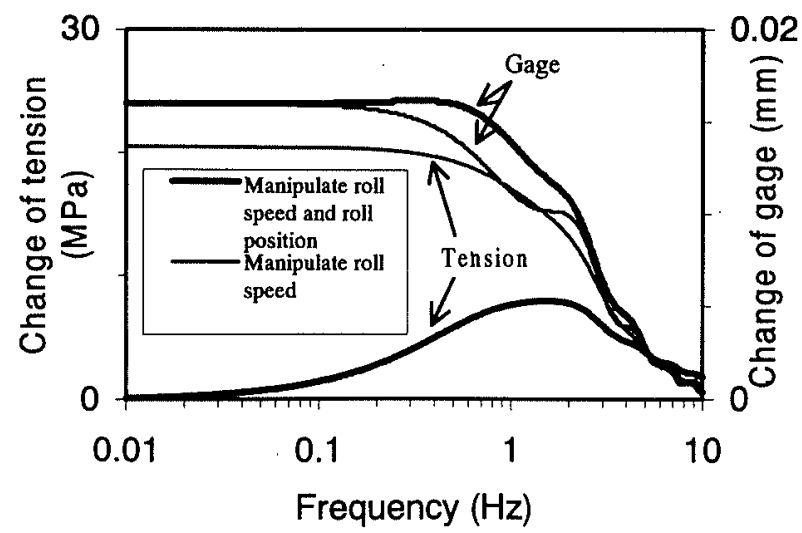

Fig. 7. Gain characteristics of change of tensile stress and gage. is exclusive for the final stand. These two controls can be alternatively applied according to rolling conditions.

\subsubsection{Rolling Force Monitor Control}

Rolling force should be controlled especially in case of rolling by dull work rolls with a rough surface, because a large coefficient of friction between the rolls and the strip easily changes rolling force. In some mills, rolling force is controlled by manipulating roll position. However, it does not seem to be a good policy, because it worsens the gage accuracy. ${ }^{6)}$ Therefore, we developed a rolling force monitor control (RFM) for rolling by dull work rolls, which manipulates reduction in thickness.

The structure of RFM combined with the non-interactive control described in Sec. 2.2 is shown in Fig. 8. RFM changes gage reference of $\# 4$ stand, according to measured rolling force at $\# 5$ stand. $\# 4$ mass-flow AGC (MF-AGC) controls exit gage of $\# 4$ stand to the modified gage reference, and this resulted in controlling the rolling force of $\# 5$ stand. $\# 5$ feedforward AGC (FF-AGC) manipulates roll position and roll speed to cancel the influence of the change of exit gage of \#4 stand on exit gage of $\# 5$ stand and the tension between $\# 4$ and $\# 5$ stand.

Figure 9 shows a simulation result of RFM during deceleration. Change of coefficient of friction is assumed to be

$$
\Delta \mu_{5}=1.0 \times 10^{-4}\left(V_{5}-6\right) \quad\left(V_{5}<6 \mathrm{~m} / \mathrm{s}\right)
$$

where $V_{5}$ represents roll speed of $\# 5$ stand. Strip width is $1 \mathrm{~m}$ and final gage is $1.2 \mathrm{~mm}$. Since exit gage of $\# 5$ stand tends to be large due to the increase of the coefficient of friction, roll position of $\# 5$ stand is referred to close and roll speed of $\# 5$ stand is referred to accelerate by $\# 5$ MF-AGC. In the case without RFM, it increases rolling force by $0.84 \mathrm{MN}$. In the case with RFM, reducing exit gage of $¥ 4$ stand by $0.01 \mathrm{~mm}$, reopening roll position and decelerating roll speed again by \#5 FF-AGC, rolling force is controlled without increasing exit gage deviation of \#5 stand.

\subsubsection{Tension Monitor Control}

In case of rolling a thin strip, a little fluctuation of tension tends to result in strip break. Especially at the

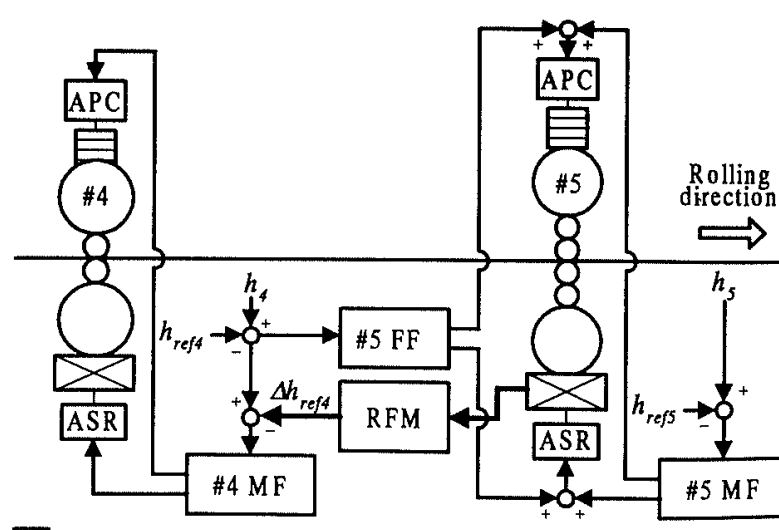

Electric screwdown $\square:$ Load cell FF: feedforward AGC MF: mass-flow AGC RFM: roll force monitor control $h_{r e f}:$ exit gage reference of \#i stand $h_{i}$ : exit gage of \#i stand $\Delta \hat{H}_{\text {ref }}$ : manipulated exit gage reference of $\# 4$ stand

ASR: automatic speed regulator APC: automatic position control

Fig. 8. Structure of rolling force monitor control. 

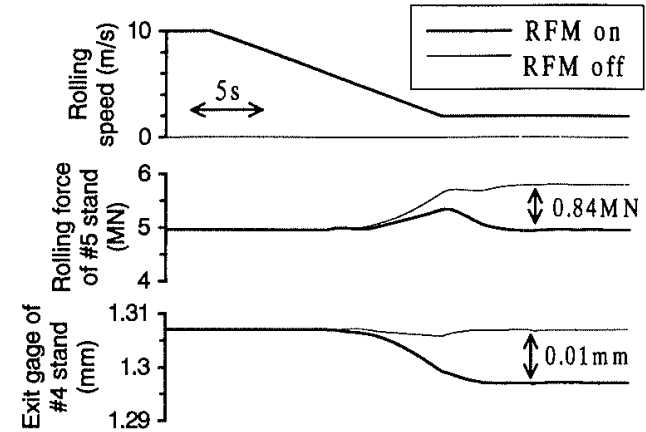

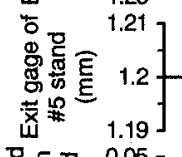

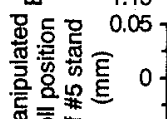

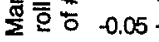

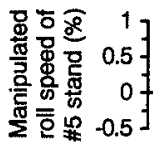

Fig. 9. Simulation result of rolling force monitor control.

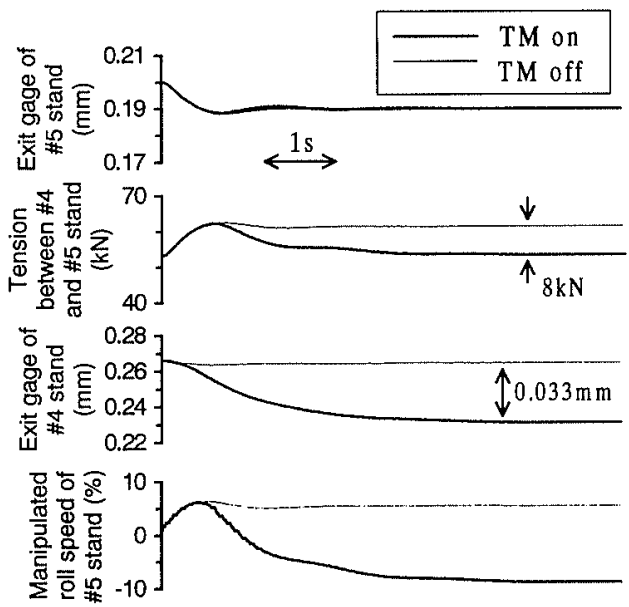

Fig. 10. Simulation result of tension monitor control

final stand, since the gage is quite thin, tension control is very important for stable rolling. Generally, tension control for manipulating roll position is often applied. However, it is not a suitable way for rolling a thin strip whose gradient of plastic curve is large, because it extremely increases the rolling force. Therefore, we propose a tension monitor control (TM) for manipulating reduction in rolling a thin strip. The structure of TM is similar to that of RFM. However, since the strip is thin, the non-interactive control is not applied.

Figure 10 shows a simulation result of TM. Strip width is $1 \mathrm{~m}$ and final gage is $0.19 \mathrm{~mm}$, and $0.01 \mathrm{~mm}$ offset of gage caused by set-up error is assumed in initial condition. Since exit gage of $\# 5$ stand is thick, roll speed of $\# 5$ stand is referred to accelerate by $\# 5$ MF-AGC. In the case without TM, \#5 MF-AGC increases strip tension between \#4 and \#5 stand by $8 \mathrm{kN}$. In the case with $\mathrm{TM}$, reducing exit gage of $\# 4$ stand by $0.033 \mathrm{~mm}$ and decelerating roll speed again by $\$ 5 \mathrm{FF}$-AGC, tension is controlled to target tension $53 \mathrm{kN}$, and this prevents any strip breakage.
Table 1. Arrangement of gage controls in simulation.

\begin{tabular}{|c|c|c|c|c|c|}
\hline & $\# 1$ & $\# 2$ & $\# 3$ & $\# 4$ & $\# 5$ \\
\hline System 1 & XM & FF & - & - & XM \\
\hline System 2 & XM, MMC & FF & - & - & XM \\
\hline System 3 & FF, XM & FF & XM & FF & XM \\
\hline System 4 & FF, XM & FF & XM & FF, MF & MF \\
\hline System 5 & FF, MF & FF, MF & FF, MF & FF, MF & FF, MF \\
\hline \multicolumn{7}{|c|}{ XM: monitor AGC FF: feedforward AGC } \\
MF: mass-flow AGC MMC: mill modulus control
\end{tabular}

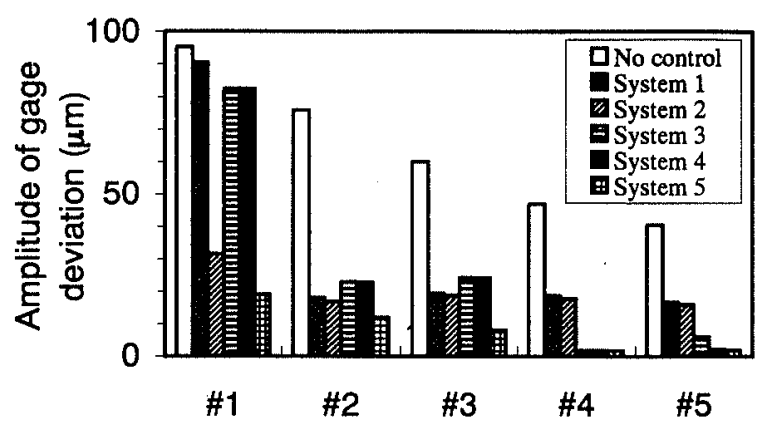

Fig. 11. Comparison of gage deviation in different arrangements of controllers (constant speed case).

\section{Application to Actual Plant}

\subsection{Arrangement of Gage Controllers}

In Sec. 2, each control method was individually described. Feedforward gage control (FF-AGC) reduces disturbance of entry gage, but it cannot compensate for the other disturbance such as variation of yield stress. Thus, it is necessary to combine FF-AGC and feedback gage control (FB-AGC). Therefore, in application to an actual plant, we investigated where the controls should be arranged by the numerical simulation model. ${ }^{7)}$ The responses of the main motors and roll position were given by Eqs. (1) and (8), where $\zeta_{v}$ is $0.9, \omega_{v} 15$, and $T_{S}$ is 0.21 . The arrangement of gage controls we examined is shown in Table 1.

System 1 is a typical gage control system for an old mill with electric screwdowns. It is equipped with $\# 1$ and \#5 monitor AGC (XM-AGC) and \#2 FF-AGC. System 2 reconstructs the electric screwdown of $\# 1$ stand whose time constant is $0.21 \mathrm{~s}$ to a hydraulic capsule whose time constant is $0.01 \mathrm{~s}$, and the mill modulus control (MMC) with the tuning factor 0.8 is installed. System 3 through System 5 do not renew the actuators, but have additional gage controls, by installing thickness gages or/and speed meters.

The gage deviation was simulated for two cases. One case was that the strip was rolled at a constant speed $20.4 \mathrm{~m} / \mathrm{s}$. The disturbance was assumed to be both of sinusoidal entry gage deviation with $50 \mu \mathrm{m}$ in amplitude and $0.05 \mathrm{~Hz}$ in frequency and sinusoidal fluctuation of yield stress with $2 \%$ in amplitude and $0.5 \mathrm{~Hz}$ in frequency.

The amplitude of the gage deviation (peak-to-peak) is shown in Fig. 11. The result without gage control is also shown. It is seen from the result of System 1 that \#1 XM-AGC is not so effective because of detection delay, but $\# 2$ FF-AGC is quite effective. In the case of System 2 , \#1 MMC decreases the gage deviation of \#1 stand, however, the deviations at $\# 2$ through $\# 5$ stand are almost 


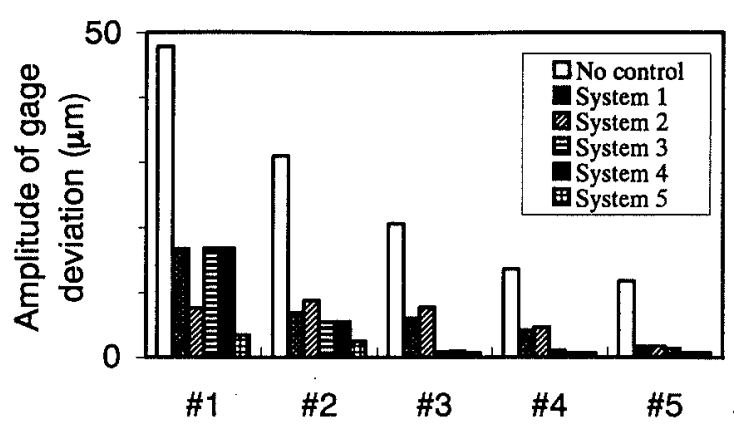

Fig. 12. Comparison of gage deviation in different arrangements of controllers (deceleration case).

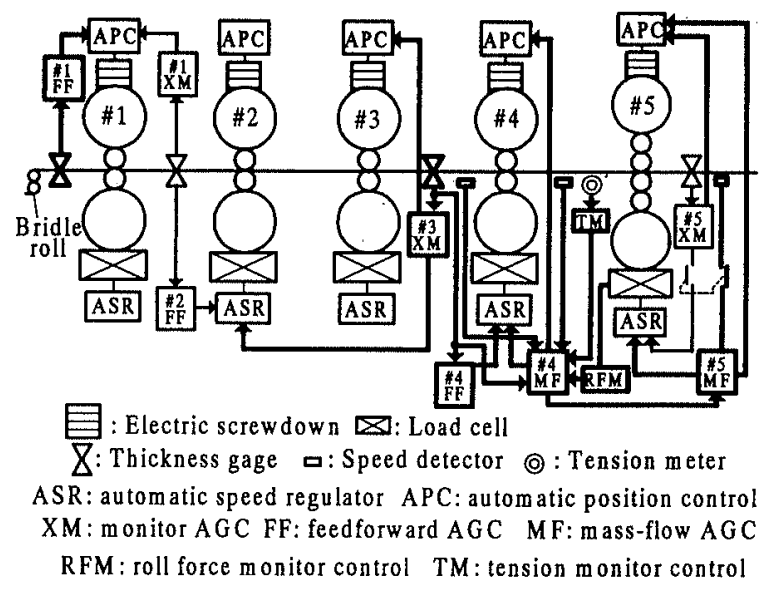

Fig. 13. Renewal of AGC system.

equivalent to those of System 1, because yield stress varies at all the stands. System 3 solves this problem considerably by \#4 FF-AGC. Furthermore, System 4 can control the influence of the variation of yield stress at $\# 4$ and $\# 5$ stands by $\# 4$ and $\# 5$ mass-flow gage controls (MF-AGC). The final gage accuracy is as good as that of System 5.

The other simulation case was that the strip was rolled in decelerating from 20.4 to $2.04 \mathrm{~m} / \mathrm{s}$ at the rate of $0.5 \mathrm{~m} / \mathrm{s}^{2}$. The disturbance was assumed to be the following variations of coefficients of friction of all the stands, according to the roll speed.

$$
\begin{array}{lc}
\Delta \mu_{1}=2.7 \times 10^{-3}\left(V_{1}-3.33\right)^{2} & \left(V_{1}<1.2 \mathrm{~m} / \mathrm{s}\right) \\
\Delta \mu_{2}=6.0 \times 10^{-4}\left(V_{2}-5.0\right)^{2} & \left(V_{2}<5.0 \mathrm{~m} / \mathrm{s}\right) \\
\Delta \mu_{3}=3.47 \times 10^{-4}\left(V_{3}-5.0\right)^{2} & \left(V_{3}<5.0 \mathrm{~m} / \mathrm{s}\right) \\
\Delta \mu_{4}=6.75 \times 10^{-5}\left(V_{4}-6.7\right)^{2} & \left(V_{4}<6.7 \mathrm{~m} / \mathrm{s}\right) \\
\Delta \mu_{5}=1.0 \times 10^{-4}\left(V_{5}-6.0\right)^{2} & \left(V_{5}<6.0 \mathrm{~m} / \mathrm{s}\right) \ldots
\end{array}
$$

The results is shown in Fig. 12. It is seen from the result of System 1 that since the variation of coefficient of friction is relatively slow, $\# 1 \mathrm{XM}$-AGC is effective as well as $\# 2$ FF-AGC. In the case of System 2, \#1 MMC decreases the gage deviation of $\# 1$ stand, however, the deviations at $\# 2$ through $\# 5$ stand are almost equivalent to those of System 1, because the coefficient of friction varies at all the stands. System 3 solves this problem considerably by \#4 FF-AGC. Furthermore, System 4 can control the influence of the variations of the coefficients of friction at $\# 4$ and $\# 5$ stands by $\# 4$ and $\# 5$ MF-AGCs.

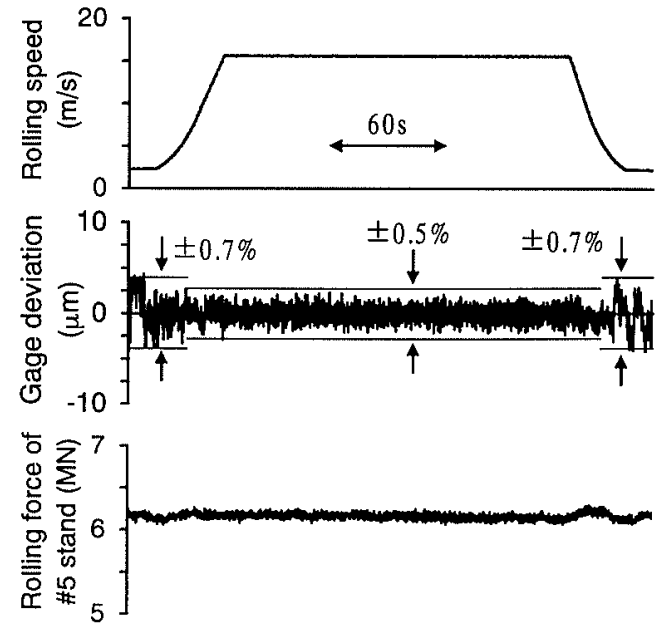

Fig. 14. Example of exit gage deviation of $\$ 5$ stand.

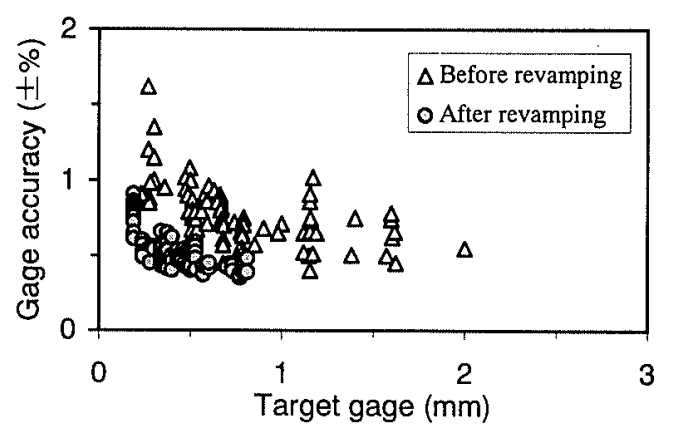

Fig. 15. Comparison of gage accuracy between the times before revamping and after revamping.

The final gage accuracy is as good as that of System 5 .

These two simulation concludes that FF-AGC at the down stream stand is superior to MMC at \#1 stand utilizing hydraulic capsule, and the addition of MF-AGC to the down stream stand improves the gage accuracy more. FF-AGC and FB-AGC at \#1 stand can control entry gage deviation whose frequency is relatively low, but cannot control variation of yield stress whose frequency is relatively high.

\subsection{Application Results}

We applied the control methods described in Sec. 2 to a 5-stand cold tandem mill at Wakayama Works. ${ }^{8)}$ The structure of the control system is shown in Fig. 13. The arrangement of the controllers was reformed from System 1 , shown in the thin lines, to System 4 , shown in the thin and thick lines. In $\# 1$ FF-AGC, the controller shown in Eq. (11) rather than Eq. (12) was installed. The noninteractive control is applied to $\# 3 \mathrm{XM}$-AGC, $\# 4$ and $\# 5$ MF-AGCs in rolling a strip whose gage is over $1.1 \mathrm{~mm}$. The rolling force monitor control is used in rolling by dull work rolls, and the tension monitor control is used in rolling a strip whose gage is thinner than $0.31 \mathrm{~mm}$.

Figure 14 shows an example of exit gage deviation at \#5 stand. Strip width was $1.076 \mathrm{~m}$, the delivery gage was $0.53 \mathrm{~mm}$, and it was rolled by dull work rolls. Gage was controlled within $\pm 0.5 \%$ of target value in steady rolling, and $\pm 0.7 \%$ during acceleration or declaration. Furthermore, the rolling force of $\# 5$ stand hardly varied by means of the rolling force monitor control even during ac- 
celeration or deceleration.

Figure 15 compares the final gage accuracy during steady rolling between the times before revamping and after revamping. The gage accuracy was quite improved for all target gage. The effect was remarkable especially when a strip was thin. This was because the reform of the controllers was more effective for a thin strip with high frequency gage deviation. As a result, the gage accuracy almost matched the accuracy of a newly constructed mill.

\section{Conclusions}

This paper described the renewal of the automatic gage control system for a cold tandem mill with electric screwdowns. We studied the way for improving gage accuracy without reconstructing actuators, from the viewpoint of reducing cost. The results are as follows.

(1) Feedforward gage controllers were redesigned to cancel the frequency characteristics from the manipulated reference of the actuator to the exit gage, and it expanded the controllable frequency range of feedforward AGC to a higher frequency.

(2) In the feedback gage control when rolling a thick strip, additional manipulation of the roll position to that of the roll speed reduced tension change caused by the gage control.

(3) At the final stand, the control of strip tension or rolling force by means of manipulating the reduction in thickness made the gage control and stable rolling compatible.

(4) Feedforward gage control and mass-flow gage control at the down stream stands were necessary for compensating for the variation of yield stress and the coefficient of friction.

The revamp of the gage control system of a cold tandem mill with electric screwdowns, which was based on this research, resulted in a great improvement of gage accuracy, and this accuracy almost matched the accuracy of a newly constructed mill.

Since the controllable frequency range of gage control system depends on the response of the actuators and the frequency characteristics of the rolling process, there exist two ways to reduce gage deviation. One is to quicken the response of the actuators by installing hydraulic capsules and $\mathrm{AC}$ motors, and the other is to improve the frequency characteristic of the rolling process by a control method. It is clear that combining the two ways results in the best gage accuracy, however, in case of renewal of gage control system for an old-fashioned mill, revamping the actuators requires much costs. Thus, designing a control method is especially important. The application results implies that the effects of improving the frequency characteristics by the control methods described in this paper are almost equivalent to those of quickening the response of the actuators.

\section{REFERENCES}

1) K. Kondo, Y. Misaka, M. Okamoto, Y. Matsumori and T. Miyagi: Trans. Iron Steel Inst. Jpn., 28 (1988), 507.

2) M. Yamashita, K. Isobe, Y. Yarita, T. Saito and Y. Yamada:
Proc. of the 1994 Japanese Spring Conf. for the Technology of Plasticity, the Jpn. Soc. Technol, Plast., Tokyo, (1994), 21.

3) K. Shigematsu, T. Kaneko, T. Matsushige, F. Nishinura, A Tomizawa, M. Eto, T. Ooi and Y. Washikita: Tetsu-to-Hagané, 83 (1997), 54.

4) T. Ooi, F. Nishimura, T. Yanagita, S. Ban and Y. Seki: Trans. Inst. Systems, Control Information Eng., 9-6 (1996), 274.

5) T. Kaneko, K. Shigematsu, A. Tomizawa, T. Nakano, T. Hayashi and T. Kajihara: Proc. of METEC Cong. 94, German Iron and Steel Institute, Düsseldorf, 2 (1994), 229.

6) Y. Misaka: Trans. Iron Steel Inst. Jpn., 8 (1968), 86.

7) A. Yamashita, Y. Misaka, Y. Kawakami and K. Kondo: J. Jpn. Soc. Technol. Plast., 14-155 (1973), 976.

8) M. Okamoto, Y. Washikita, Y. Mori and E. Hitotsumatsu: CAMP-ISIJ, 9 (1996), 261.

\section{Appendix. Frequency Characteristics of Rolling Process}

\section{(1) Characteristics of $\# 2$ through $\# 5$ Stand ${ }^{2,3)}$}

At $\# 2$ through $\# 5$ stand, a gagemeter equation, a rolling force equation, a forward slip equation and the law of mass-flow constancy between the entry and the exit of the stand are expressed as

$$
\begin{array}{r}
\Delta h_{i}(t)=\Delta S_{i}(t)+\frac{1}{M_{i}} \Delta P_{i}(t) \ldots \ldots \ldots \ldots . .(\mathrm{A}-1) \\
\Delta P_{i}(t)=\frac{\partial P_{i}}{\partial \sigma_{i-1}} \Delta \sigma_{i-1}(t)+\frac{\partial P_{i}}{\partial h_{i}} \Delta h_{i}(t)+\frac{\partial P_{i}}{\partial H_{i}} \Delta H_{i}(t) \\
\Delta f_{i}(t)=\frac{\partial f_{i}}{\partial \sigma_{i-1}} \Delta \sigma_{i-1}(t)+\frac{\partial f_{i}}{\partial h_{i}} \Delta h_{i}(t)+\frac{\partial f_{i}}{\partial H_{i}} \Delta H_{i}(t) \\
\frac{\Delta H_{i}(t)}{h_{i-1}}+\frac{\Delta v_{\mathrm{in}, i}(t)}{V_{i-1}}=\Delta f_{i}(t)+\frac{\Delta h_{i}(t)}{h_{i}}+\frac{\Delta V_{i}(t)}{V_{i}} \ldots(\mathrm{A}-(\mathrm{A}-2)
\end{array}
$$

where $h$ represents exit gage, $H$ entry gage, $S$ roll position, $P$ rolling force, $f$ forward slip, $M$ mill modulus, $V$ roll speed, $v_{\text {in }}$ entry strip velocity, $\sigma$ front tension, $t$ time, $\Delta$ change from basic condition, and the suffix represents stand number. Roll position $\Delta S_{i}$ and roll speed $\Delta V_{i} / V_{i}$ can be a manipulated variable. For the upper stand,

$$
\begin{aligned}
& \Delta h_{i-1}(t)=\frac{1}{M_{i-1}} \Delta P_{i-1}(t) \\
& \Delta P_{i-1}(t)= \frac{\partial P_{i-1}}{\partial \sigma_{i-1}} \Delta \sigma_{i-1}(t)+\frac{\partial P_{i-1}}{\partial h_{i-1}} \Delta h_{i-1}(t) \ldots . . . . . \\
& \Delta f_{i-1}(t)=\frac{\partial f_{i-1}}{\partial \sigma_{i-1}} \Delta \sigma_{i-1}(t)+\frac{\partial f_{i-1}}{\partial h_{i-1}} \Delta h_{i-1}(t) \\
& \Delta v_{\text {out }, i-1}(t)=V_{i-1} \cdot \Delta f_{i-1}(t)
\end{aligned}
$$

are obtained, where $v_{\text {out }}$ represents exit strip velocity. $\Delta \sigma_{i-1}$ and $\Delta H_{1}$ are given by

$$
\begin{gathered}
\Delta \sigma_{i-1}(t)=\frac{E}{L_{i-1}} \int\left(\Delta v_{\mathrm{in}, i}(t)-\Delta v_{\mathrm{ou}, i-1}(t)\right) d t \ldots \\
\Delta H_{i}(t)=\Delta h_{i-1}\left(t-\frac{L_{i-1}}{V_{i-1}}\right)+\Delta H_{d, i}(t) \ldots .(\mathrm{A}-
\end{gathered}
$$

where $E$ represents Young's modulus, $L_{i-1}$ distance between $\# i-1$ and $\# i$ stand, and $H_{d}$ disturbance of $H$.

Laplace transforms of Eqs. (A-1) to (A-10) and simple 
calculation bring transfer functions from $\Delta S_{i}, \Delta V_{i} / V_{i}$ and $\Delta H_{d, i}$ to $\Delta h_{i}$ and transfer functions from $\Delta S_{i}$ and $\Delta V_{i} / V_{i}$ to $\Delta \sigma_{i-1}$ as follows.

$$
\begin{array}{r}
G_{h S}(s) \equiv \frac{\Delta h_{i}(s)}{\Delta S_{i}(s)}=\alpha_{1}+E V_{i-1} \alpha_{2}\left(\alpha_{3}+\alpha_{4} e^{-\frac{L_{i-1}}{V_{i-1}} s}\right) D(s) \\
\ldots \ldots \ldots \ldots \ldots \ldots \ldots . .(\mathrm{A}-11) \\
G_{h V}(s) \equiv \frac{\Delta h_{i}(s)}{\Delta V_{i} / V_{i}(s)}=E V_{i-1}\left(\alpha_{3}+\alpha_{4} e^{-\frac{L_{i-1}}{V_{i-1}} s}\right) D(s) \\
G_{h H_{d}}(s) \equiv \frac{\Delta h_{i}(s)}{\Delta H_{d, i}(s)}=\alpha_{5}+E V_{i-1} \alpha_{6}\left(\alpha_{3}+\alpha_{4} e^{-\frac{L_{i-1}}{V_{i-1}} s}\right) D(s) \\
G_{\sigma S}(s) \equiv \frac{\Delta \sigma_{i-1}(s)}{\Delta S_{i}(s)}=E V_{i-1} \alpha_{7} D(s) \ldots . . .(\mathrm{A}-14) \\
G_{\sigma V}(s) \equiv \frac{\Delta \sigma_{i-1}(s)}{\Delta V_{i} / V_{i}(s)}=E V_{i-1} D(s) \ldots \ldots . .(\mathrm{A}-15)
\end{array}
$$

where $\alpha_{j}$ are constants depending on $M_{i}, h_{i}$ and the partial differential coefficients, and

$$
D(s)=\left[L_{i-1} s+E V_{i-1}\left(\alpha_{8}+\alpha_{9} e^{-\frac{L_{i-1}}{V_{i-1}} s}\right)\right]^{-1}
$$

Neglecting the irrational factor $e^{-\frac{L_{i-1}}{V_{i-1}} s}$ in Eqs. (A-11) to (A-13), rational transfer functions, which are more useful for designing controllers, are obtained as

$$
\begin{aligned}
G_{h S}^{\prime}(s) & =c_{h S} \cdot \frac{T^{\prime} s+1}{T s+1} . \\
G_{h V}^{\prime}(s) & =c_{h V} \cdot \frac{1}{T s+1} . \\
G_{h H_{d}}^{\prime}(s) & =c_{h H_{d}} \cdot \frac{T^{\prime \prime} s+1}{T s+1}
\end{aligned}
$$

where $c_{h s}, c_{h V}$ and $c_{h H_{d}}$ are constants derived from $\alpha_{j}$ and

$$
\begin{array}{r}
T=\frac{L_{i-1}}{E V_{i-1} \alpha_{8}} \ldots \ldots \ldots \ldots \ldots . . . . . . \\
T^{\prime}=\frac{L_{i-1}}{E V_{i-1}\left(\alpha_{8}+\frac{\alpha_{2} \alpha_{3}}{\alpha_{1}}\right)}(>T) \\
T^{\prime \prime}=\frac{L_{i-1}}{E V_{i-1}\left(\alpha_{8}+\frac{\alpha_{3} \alpha_{6}}{\alpha_{5}}\right)}(<T)
\end{array}
$$

\section{(2) Characteristics of \#1 Stand ${ }^{4)}$}

At $\# 1$ stand, the law of mass-flow constancy between entry and exit of the stand is expressed as

$$
\frac{\Delta H_{d, 1}(t)}{h_{0}}+\frac{\Delta v_{\mathrm{in}, 1}(t)}{V_{0}}=\Delta f_{1}(t)+\frac{\Delta h_{1}(t)}{h_{1}}
$$

where the suffix 0 represents the bridle roll, which is equipped at the entry of the mill. For the bridle roll, motor torque $\tau$ and strip velocity $v_{\text {out }, 0}$ are given by

$$
\begin{gathered}
\Delta \tau(t)=\frac{R h_{0} B}{\eta} \Delta \sigma_{0}(t)+\Delta \tau_{\text {ref }}(t) \\
\Delta v_{\text {out }, 0}(t)=\frac{R}{\eta J} \int \Delta \tau(t) d t \quad \ldots
\end{gathered}
$$

where $R$ represents radius of the bridle roll, $\eta$ gear ratio of the motor, $B$ strip width, $\tau_{\text {ref }}$ manipulated torque of the motor, and $J$ moment of inertia of the bridle roll. Roll position $\Delta S_{1}$ and torque $\Delta \tau_{\text {ref }}$ can be a manipulated variable. $\Delta \sigma_{0}$ is given by

$$
\Delta \sigma_{0}(t)=\frac{E}{L_{0}} \int\left(\Delta v_{\mathrm{in}, 1}(t)-\Delta v_{\mathrm{out}, 0}(t)\right) d t
$$

where $L_{0}$ represents distance between the bridle roll and $\# 1$ stand. Laplace transforms of Eqs. (A-1) to (A-3) and Eqs. (A-23) to (A-26), and simple calculation bring transfer functions from $\Delta S_{1}, \Delta \tau_{\text {ref }}$ and $\Delta H_{d, 1}$ to $\Delta h_{1}$ as follows.

$$
\begin{aligned}
G_{h S}(s) & \equiv \frac{\Delta h_{1}(s)}{\Delta S_{1}(s)}=c_{h s} \cdot \frac{s^{2}+2 \zeta^{\prime} \omega_{n} s+\omega_{n}^{2}}{s^{2}+2 \zeta \omega_{n} s+\omega_{n}^{2}} \ldots \\
G_{h \tau}(s) & \equiv \frac{\Delta h_{1}(s)}{\Delta \tau_{\mathrm{ref}}(s)}=c_{h \tau} \cdot \frac{\omega_{n}^{2}}{s^{2}+2 \zeta \omega_{n} s+\omega_{n}^{2}} \ldots \\
G_{h H_{d}}(s) & \equiv \frac{\Delta h_{1}(s)}{\Delta H_{d, 1}(s)}=c_{h H_{d}} \cdot \frac{s^{2}+2 \zeta^{\prime \prime} \omega_{n} s+\omega_{n}^{2}}{s^{2}+2 \zeta \omega_{n} s+\omega_{n}^{2}}
\end{aligned}
$$

where $c_{h s}, c_{h \tau}$ and $c_{h H_{d}}$ are constants derived from $\alpha_{j}$, and

$$
\begin{aligned}
& \omega_{n}=\frac{R}{\eta} \sqrt{\frac{h_{0} B E}{J L_{0}}} \\
& \zeta=-\frac{V_{0} \eta}{2 R} \sqrt{\frac{J E}{h_{0} B L_{0}}} \alpha_{10} \\
& \zeta^{\prime}=-\frac{V_{0} \eta}{2 R} \sqrt{\frac{J E}{h_{0} B L_{0}}}\left(\alpha_{10}-\frac{\alpha_{2} \alpha_{3}}{\alpha_{1}}\right)(<\zeta) \\
& \zeta^{\prime \prime}=-\frac{V_{0} \eta}{2 R} \sqrt{\frac{J E}{h_{0} B L_{0}}}\left(\alpha_{10}-\frac{\alpha_{3} \alpha_{6}}{\alpha_{5}}\right)(>\zeta)
\end{aligned}
$$

